\title{
PERBEDAAN PENGETAHUAN STRUKTUR ANATOMI NORMAL RADIOGRAF PANORAMIK ANTARA MAHASISWA PREKLINIK DAN KLINIK
}

\author{
Sania Hana Sangi*, Shinta Amini Prativi**, Sekar Putri ${ }^{* *}$ \\ *Mahasiwa preklinik, Bagian Kedokteran Gigi dan Mulut FK Universitas Sriwjaya \\ **Bagian Kedokteran Gigi dan Mulut FK Universitas Sriwjaya \\ e-mail: saniasangi@gmail.com
}

\section{KATA KUNCI}

anatomi normal, panoramik, pengetahuan

\begin{abstract}
ABSTRAK
Latar belakang: Adanya kesalahan interpretasi dapat menyebabkan kesalahan dalam mendiagnosis yang berujung pada kesalahan perawatan. Keakuratan dalam mengidentifikasi struktur anatomi normal akan membantu praktisi kedokteran gigi untuk menginterpretasi hasil radiograf. Tujuan penelitian ini adalah untuk mengetahui perbedaan pengetahuan mahasiswa preklinik dan klinik bagian kedokteran gigi dan mulut Universitas Sriwijaya mengenai struktur anatomi normal radiograf panoramik. Metode: Penelitian ini adalah survei analitik dengan pendekatan potong lintang (cross sectional). Penelitian ini melibatkan 100 subjek. Subjek penelitian terdiri atas kelompok mahasiswa preklinik $(n=50)$ dan mahasiswa klinik $(n=50)$. Pengetahuan struktur anatomi normal diukur menggunakan metode kuesioner online melalui Google form. Kuesioner berisi 15 pertanyaan pilihan ganda sambil diperlihatkan foto panoramik dengan waktu maksimal 20 menit. Data dianalisis menggunakan uji Mann-Whitney. Hasil: Hasil yang diperoleh struktur anatomi prosesus kondiloideus, tuberositas maksilaris, sinus maksilaris, palatum durum, inferior border of mandible, ramus mandibula, cervical vertebrae, artikularis eminensia, kanalis mandibularis, foramen mentalis dan submandibular gland fossa cukup baik diketahui oleh mahasiswa preklinik dan klinik. Pengetahuan prosesus koronoideus dan nasopharyngeal air space cukup rendah, terutama prosesus stiloideus dan lidah cukup rendah pada kedua kelompok. Nilai rerata skor pengetahuan pada kelompok mahasiswa preklinik lebih rendah namun tidak bermakna dibandingkan kelompok mahasiwa klinik $(p>0,05)$. Kesimpulan: Mahasiswa preklinik dan klinik kedokteran gigi dan mulut Universitas Sriwijaya sama-sama memiliki pengetahuan yang cukup baik mengenai struktur anatomi normal radiograf panoramik.
\end{abstract}




KEYWORDS

normal anatomy, panoramic, knowledge

\begin{abstract}
Background: Accuracy in identified normal anatomical structures would help dentistry practitioners interpreted radiographs. The objective of this study was to determine differences in knowledge of the normal anatomical structure of panoramic radiography between preclinical and clinical students in the dentistry study program of Sriwijaya University. Method: The present study was an analytic survey with a cross-sectional approach. A total of 100 subjects consisted of preclinical students groups $(n=50)$ and clinical students $(n=50)$ were included in this study. Knowledge of normal anatomical structures was measured using the questionnaire. The duration of the examination was 20 minutes. Data were analyzed using the MannWhitney test. Results: The results obtained the anatomical structure of mandibular condyle, maxillary tuberosity, maxillary sinus, hard palate, inferior border of the mandible, ramus of the mandible and cervical vertebrae, articular eminence, mandibular canal, mental foramen, and submandibular gland fossa were quite well known by preclinical and clinical students. Knowledge of the coronoid process and nasopharyngeal airspace were quite a low known, especially styloid process and tongue in both groups. The mean value of the total score in the preclinical students' group was lower than the clinical students' group but was not significant ( $p>0.05)$. Conclusion: Preclinical and clinical students in the dentistry study program of Sriwijaya University both have a fairly good knowledge of the normal anatomical structure of panoramic radiography.
\end{abstract}

\section{PENDAHULUAN}

Radiograf panoramik adalah teknik radiograf untuk menghasilkan gambar tunggal dari struktur wajah yang mencakup lengkung gigi rahang atas dan rahang bawah serta struktur pendukungnya. ${ }^{1,2}$ Adapun keterbatasan utama radiograf panoramik adalah distorsi dan superimposed yang dapat diperburuk oleh kesalahan teknis selama pemrosesan film sehingga menimbulkan kesulitan dalam melakukan interpretasi. ${ }^{1,3-5}$ Interpretasi radiograf yang baik dan benar sangat penting untuk membedakan antara struktur anatomi normal dan kelainan sehingga mendukung keberhasilan perawatan. ${ }^{2}$
Adanya kesalahan interpretasi dapat menyebabkan kesalahan dalam mendiagnosa yang berujung pada kesalahan perawatan. ${ }^{6}$ Beberapa struktur anatomi normal dapat menyerupai gambaran abnormal sehingga menyebabkan kesalahan interpretasi. Lakshman et al melaporkan kasus struktur anatomi normal foramen mentalis menyerupai kelainan periapikal sedangkan Ramugade et al melaporkan kasus lesi periapikal yang menyerupai foramen mentalis. ${ }^{7-9}$ Struktur anatomi normal lainnya seperti submandibular gland fossa dapat salah diinterpretasikan sebagai stafne bone cyst. ${ }^{10}$ 
Keakuratan dalam mengidentifikasi struktur anatomi normal akan membantu praktisi kedokteran gigi dalam melakukan perawatan untuk menghindari terjadinya komplikasi. ${ }^{8,11}$ Pada perawatan kedokteran gigi seperti pencabutan dan perawatan saluran akar gigi posterior rahang atas, pengetahuan struktur anatomi normal akan membantu praktisi kedokteran gigi meminimalisir terjadinya komplikasi perforasi sinus maksilaris dan mengalami parestesia. $^{12}$ Perawatan kedokteran gigi lainnya, dental implant perlu penentuan anatomi yang benar berperan penting dalam mencegah terjadinya komplikasi seperti perdarahan, hemorrhage dan parestesia. ${ }^{13}$

Konsil Kedokteran Indonesia menyatakan bahwa kemampuan interpretasi hasil pemeriksaan radiograf menjadi salah satu standar kompetensi dokter gigi Indonesia. ${ }^{14}$ Mahasiswa kedokteran gigi yang telah menerima mata kuliah radiologi kedokteran gigi harus mampu menginterpretasi gambaran radiograf panoramik sebagai bekal menjadi seorang dokter gigi dalam menegakkan diagnosis dan menentukan rencana perawatan. Mahasiswa klinik juga melakukan pemeriksaan radiograf terhadap pasien untuk membantu menegakkan diagnosis. ${ }^{15}$

Penelitian Maeda et al melaporkan bahwa mahasiswa tahun ke-5 dan mahasiswa tahun ke-6 sulit mengidentifikasi struktur jaringan lunak dan airway space dibandingkan dengan struktur tulang. ${ }^{16}$ Penelitian Ilguy et al melaporkan bahwa dari sejumlah tingkatan mahasiswa terdapat beberapa struktur anatomi normal yang persentase jawabannya rendah seperti artikularis eminensia, lidah, sinus maksilaris, prosesus kondiloideus dan nasopharyngeal air space sulit diidentifikasi. Ilguy et al juga melaporkan bahwa antara tingkatan kelas menunjukan tingkat pengetahuan yang signifikan dengan pengetahuan struktur anatomi normal radiograf panoramik. ${ }^{15}$

Hal tersebut tidak menutup kemungkinan terjadi pada mahasiswa bagian kedokteran gigi dan mulut Universitas Sriwijaya mempunyai perbedaan pengetahuan struktur anatomi normal radiograf panoramik. Tujuan penelitian untuk mengetahui perbedaan pengetahuan mahasiswa preklinik dan klinik bagian kedokteran gigi dan mulut di lingkungan Universitas Sriwijaya mengenai struktur anatomi normal radiograf panoramik.

\section{METODE}

Jenis penelitian yang digunakan dalam penelitian ini adalah penelitian survei analitik dengan pendekatan potong lintang (cross sectional). Penelitian ini dilakukan pada bulan Desember 2019 di Bagian Kedokteran Gigi dan Mulut (BKGM) Universitas Sriwjiya dan Rumah Sakit Khusus Gigi dan Mulut (RSKGM) Sumatera Selatan.

Penelitian ini menggunakan kuesioner yang disajikan dalam kuesioner online melalui 
google form yang berisi 15 pertanyaan pilihan ganda. Satu radiograf panoramik yang dianggap memiliki kualitas baik dan telah ditandai dengan nomor sesuai urutan pertanyaan (Gambar 1) ditampilkan di tablet $P C$. Subjek akan dibagikan link google form dan diberi waktu maksimal 20 menit untuk mengisi kuesioner.

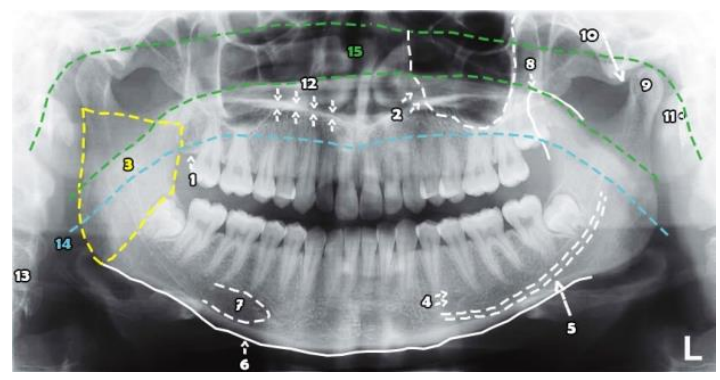

Gambar 1. Radiograf panoramik yang telah ditandai.

Subjek penelitian ini terdiri dari 100 mahasiswa yang terdiri dari mahasiswa preklinik bagian kedokteran gigi dan mulut Universitas Sriwijaya tahun ke-4 $(n=50)$ dan mahasiswa klinik bagian kedokteran gigi dan mulut Universitas Sriwijaya tahun ke-2 di Rumah Sakit Khusus Gigi dan Mulut (RSKGM) Sumatera Selatan $(n=50)$. Mahasiswa yang telah mengikuti mata kuliah Radiologi Kedokteran Gigi 1 - 6, sedang dan selesai mengikuti diskusi Radiologi Kedokteran Gigi. Seluruh subjek yang memenuhi kriteria diberikan penjelasan mengenai prosedur penelitian dan diminta untuk menandatangani informed consent.

Jawaban kuesioner akan direkapitulasi secara otomatis oleh Google form, yaitu untuk menghitung rata-rata skor setiap kelompok dengan cara menghitung skor total dari setiap subjek didapatkan dari jumlah jawaban yang benar dibagi jumlah total pertanyaan dikali 100, kemudian skor subjek setiap kelompok akan dihitung rata-ratanya, lalu untuk menghitung persentase jawaban benar setiap struktur anatomi normal dengan cara menghitung total benar setiap kelompok per struktur anatomi normal dibagi jumlah subjek per kelompok kemudian dikali 100\% yang ditampilkan dalam tabel persentase.

Normalitas skor diperiksa menggunakan uji Shapiro-Wilk, lalu dilanjutkan uji homogenitas dan ditemukan data berdistribusi tidak normal. Perbedaan pengetahuan mengenai struktur anatomi normal radiograf panoramik antara kelompok mahasiswa preklinik dan klinik dianalisis menggunakan Uji Mann-Whitney.

Nilai-p dari 0,05 dianggap signifikan secara statistik. Penelitian ini telah diajukan uji kelayakan etik (ethical clearance) oleh Komisi Etik Penelitian Rumah Sakit Umum Pusat Mohammad Hosein Palembang dan Fakultas Kedokteran Universitas Sriwijaya dengan nomor 602/kepkrsmhfkunsri/2019.

\section{HASIL}

Penelitian tentang perbedaan pengetahuan struktur anatomi normal radiograf panoramik antara mahasiswa preklinik dan klinik (studi di bagian Kedokteran Gigi dan Mulut Universitas Sriwijaya) telah dilakukan. Subjek penelitian ini melibatkan 100 orang 
yang telah memenuhi kriteria inklusi. Persentase jawaban benar struktur anatomi normal pada setiap kelompok dapat dilihat pada tabel 1.

Tabel 1. Persentase jawaban benar struktur anatomi normal pada radiograf panoramik.

\begin{tabular}{lcc}
\hline Landmark anatomi & $\begin{array}{c}\text { Mahasiswa } \\
\text { preklinik } \\
\text { n (\%) }\end{array}$ & $\begin{array}{c}\text { Mahasiswa } \\
\text { klinik } \\
\text { n (\%) }\end{array}$ \\
\hline $\begin{array}{l}\text { Sinus maksilaris } \\
\text { Tuberositas } \\
\text { maksilaris }\end{array}$ & $47(94 \%)$ & $47(94 \%)$ \\
$\begin{array}{l}\text { Palatum durum } \\
\text { Kanalis } \\
\text { mandibularis }\end{array}$ & $46(98 \%)$ & $47(94 \%)$ \\
$\begin{array}{l}\text { Foramen mentalis } \\
\text { Submandibular } \\
\text { gland fossa }\end{array}$ & $38(76 \%)$ & $46(92 \%)$ \\
$\begin{array}{l}\text { Inferior border of } \\
\text { mandible }\end{array}$ & $39(78 \%)$ & $49(90 \%)$ \\
$\begin{array}{l}\text { Ramus mandibula } \\
\text { Prosesus } \\
\text { kondiloideus }\end{array}$ & $44(88 \%)$ & $38(76 \%)$ \\
$\begin{array}{l}\text { Prosesus } \\
\text { koronoideus }\end{array}$ & $43(86 \%)$ & $48(96 \%)$ \\
$\begin{array}{l}\text { Artikularis } \\
\text { eminensia }\end{array}$ & $50(100 \%)$ & $48(98 \%)$ \\
$\begin{array}{l}\text { Prosesus stiloideus } \\
\text { Cervical vertebrae }\end{array}$ & $20(76 \%)$ & $26(52 \%)$ \\
$\begin{array}{l}\text { Lidah } \\
\text { Nasopharyngeal air } \\
\text { space }\end{array}$ & $27(88 \%)$ & $16(32 \%)$ \\
\hline
\end{tabular}

Berdasarkan tabel diatas, struktur anatomi yang paling banyak dijawab benar adalah prosesus kondiloideus oleh kelompok mahasiswa preklinik sebanyak 50 subjek (100\%). Pada kelompok mahasiswa klinik, struktur anatomi yang paling banyak dijawab benar adalah ramus mandibula sebanyak 49 subjek (98\%). Struktur anatomi yang paling sedikit dijawab benar oleh dua kelompok ini yaitu struktur anatomi lidah, sebanyak 25 subjek (50\%) pada kelompok mahasiswa preklinik dan sebanyak 15 subjek (30\%) pada kelompok mahasiswa klinik.
Tabel 2. Distribusi subjek penelitian kelompok mahasiswa preklinik dan klinik.

\begin{tabular}{ccc}
\hline Karakteristik & $\begin{array}{c}\text { Mahasiswa } \\
\text { preklinik } \\
(\mathbf{n = 5 0})\end{array}$ & $\begin{array}{c}\text { Mahasiswa } \\
\text { klinik } \\
(\mathbf{n = 5 0})\end{array}$ \\
\hline Jenis kelamin & & \\
Laki-laki & 4 & 3 \\
Perempuan & 46 & 47 \\
Rata-rata skor & 76,93 & 78,13 \\
\hline
\end{tabular}

Tabel 2 menunjukkan bahwa dari seluruh sampel lebih dari setengah sampel adalah perempuan dan sisanya adalah laki - laki. Pada kelompok mahasiswa klinik, jumlah sampel perempuan yang mengisi kuesioner lebih banyak dibandingkan kelompok mahasiswa preklinik yang berjumlah 47 orang sedangkan pada kelompok mahasiswa preklinik berjumlah 46 orang. Rerata skor antara kelompok mahasiswa preklinik dan klinik berbeda yaitu rata-rata skor kelompok mahasiswa preklinik lebih rendah sebesar 76,93 dibandingkan kelompok mahasiswa klinik sebesar 78,13.

Data skor dilakukan uji normalitas untuk melihat sebaran data. Uji normalitas menggunakan uji Shapiro-Wilk dengan hasil data tidak terdistribusi normal $(\mathrm{p}<0,05)$. Usaha transformasi data tidak berhasil menormalkan data $(\mathrm{p}<0,05)$. Skor tidak memenuhi syarat untuk diteruskan ke uji $\mathrm{T}$ tidak berpasangan sehingga data dianalisis menggunakan uji Mann-Whitney. 
Tabel 3. Analisis uji Mann-Whitney perbedaan skor antara mahasiswa preklinik dan mahasiswa klinik.

\begin{tabular}{lccc}
\hline & $\begin{array}{c}\text { Mahasiswa } \\
\text { preklinik }\end{array}$ & $\begin{array}{c}\text { Mahasiswa } \\
\text { klinik }\end{array}$ & \\
\cline { 2 - 3 } & $\begin{array}{c}\text { Median } \\
\text { (Minimum- } \\
\text { Maksimum) }\end{array}$ & $\begin{array}{c}\text { Median } \\
\text { (Minimum- } \\
\text { Maksimum) }\end{array}$ & \\
\hline \multirow{2}{*}{ Skor } & $\begin{array}{c}80,00(53,33- \\
100,00)\end{array}$ & $\begin{array}{c}80,00(53,33- \\
100,00)\end{array}$ & 0,61 \\
\hline
\end{tabular}

Analisis uji Mann-Whitney, diperoleh nilai $\mathrm{p}$ skor 0,61. Hasil analisis uji Mann-Whitney menunjukkan bahwa secara statistik tidak terdapat perbedaan bermakna skor antara kelompok mahasiswa preklinik dan mahasiswa klinik ( $p>0,05)$ (Tabel 3).

\section{PEMBAHASAN}

Pengetahuan mahasiswa preklinik dan klinik kedokteran gigi dan mulut Universitas Sriwijaya mengenai struktur anatomi radiograf panoramik sudah cukup baik, ditunjukkan pada persentase jawaban benar kelompok mahasiswa preklinik dan klinik cukup tinggi. Hasil penelitian pada kedua kelompok menunjukkan bahwa mahasiswa preklinik merupakan kelompok dengan skor pengetahuan kurang baik dari mahasiswa klinik.

Pengetahuan struktur anatomi yang paling tinggi diketahui pada kedua kelompok ini adalah prosesus kondiloideus. Pada kelompok mahasiswa preklinik, persentase jawaban benar prosesus kondiloideus sebesar $100 \%$ dan pada kelompok mahasiswa klinik sebesar 96\%. Hal ini dikarenakan gambaran struktur anatomi prosesus kondiloideus tidak ada superimposisi dan prosesus kondiloideus merupakan struktur anatomi jaringan keras yang memunculkan gambaran radiopak, sehingga gambaran sangat jelas.

Struktur anatomi tuberositas maksilaris, sinus maksilaris, palatum durum, inferior border of mandible, ramus mandibula, cervical vertebrae dan artikularis eminensia cukup tinggi diketahui oleh mahasiswa preklinik dan klinik. Beberapa struktur anatomi ini banyak diketahui karena gambarannya radiopak dan densitasnya cukup baik sehingga dapat dibedakan dengan struktur anatomi lain, tetapi masih terdapat beberapa subjek salah menjawab pertanyaan cervical vertebrae sebagai ear lobe karena overlap. ${ }^{17,18}$ Foramen mentalis dan kanalis mandibularis juga merupakan struktur anatomi yang cukup baik diketahui oleh kedua kelompok ini karena gambarannya radiolusen yang cukup jelas dan tidak terlalu superimposisi dengan struktur anatomi lain.

Hasil penelitian pada kedua kelompok menunjukkan bahwa pengetahuan mahasiswa preklinik dan klinik terhadap lidah dan prosesus stiloideus cukup sulit diketahui. Struktur anatomi lain yang kurang dipahami oleh kedua kelompok ini adalah prosesus koronoideus, submandibular gland fossa dan nasopharyngeal air space. Mahasiswa sulit mengidentifikasi prosesus stiloideus dan prosesus koronoideus karena gambarannya superimposisi, sehingga sulit diidentifikasi baik antara mahasiswa preklinik dan klinik. Faktor lainnya yaitu gambaran radiolusen lidah, submandibular gland fossa dan nasopharyngeal air space yang 
menyebabkan sulit untuk diketahui. Hal ini sejalan dengan penelitian Maeda et al yang melaporkan bahwa banyak mahasiwa kedokteran gigi kurang mengerti mengenai posisi gambaran radiolusen antara jaringan lunak dan air layer. ${ }^{19}$

Hasil rata-rata skor pada penelitian ini juga menunjukkan bahwa mahasiswa preklinik memiliki nilai rerata skor yang lebih rendah dibandingkan mahasiswa klinik. Faktorfaktor yang mungkin berkaitan dengan pengetahuan struktur anatomi yaitu dapat disebabkan kurangnya perhatian mahasiwa preklinik untuk mengetahui struktur anatomi normal dan waktu pembelajaran radiologi kedokteran gigi mahasiswa preklinik kurang dibandingkan mahasiwa klinik. ${ }^{19}$ Mahasiswa klink yang sedang atau sudah menjalani diskusi radiologi kedokteran gigi pastinya lebih banyak memiliki pengetahuan radiologi kedokteran gigi terutama dalam hal interpretasi foto. Pada saat melihat keadaan rongga mulut pasien, mahasiswa klinik harus mampu menginterpretasi gambaran radiograf untuk menentukan rencana perawatan.

Pada penelitian ini, subjek mengidentifikasi struktur anatomi dengan cara memilih jawaban dari soal pilihan ganda. Soal pilihan ganda dapat mempermudah subjek menjawab pertanyaan pilihan ganda dengan cepat dibandingkan soal tanpa pilihan ganda, namun kekurangannya yaitu subjek hanya mengisi pertanyaan dengan cara menebak jawaban yang benar dari pilihan ganda tersebut. Sebaiknya butir pilihan ganda lebih memilih struktur anatomi yang berdekatan dan densitas yang serupa. Tempat pelaksanaan penelitian juga harus diperhatikan, idealnya yaitu suasana yang tenang, tempatnya memiliki pencahayaan yang baik untuk membaca foto radiograf. Setiap subjek sebaiknya menggunakan satu tablet $p c$ supaya objektifitasnya terjaga dan didapatkan hasil yang valid.

\section{SIMPULAN}

Tidak terdapat perbedaan bermakna mengenai pengetahuan struktur anatomi normal radiograf panoramik antara mahasiswa preklinik dan klinik di bagian kedokteran gigi dan mulut Universitas Sriwijaya.

\section{DAFTAR PUSTAKA}

1. Mallya SM, Lam EWN. White and Pharoah oral radiology: Principles and interpretation. $8^{\text {th }}$ ed. Canada: Elsevier; 2014. p.419-462.

2. McNab S, Monsour P, Madden D, Gannaway D. Knowledge of undergraduate and graduate dentists and dental therapists concerning panoramic radiographs: Knowledge of panoramic radiographs. Open Journal of Dentistry and Oral Medicine. 2015; 3(2): 46-52. https://pdfs.semanticscholar.org/f453/0c ac20c0468801d950cf89872aafca8f4cfd. pdf

3. Misch CE, Resnik RR. Dental implant prosthetics. $2^{\text {nd }}$ ed. Mosby: Elsevier; 2015.p.130-5.

4. Watanabe PCA, Faria V, Camargo AJ. Multiple radiographic analysis (Systemic disease): Dental panoramic radiography. J Oral Health Dent Care. 2017; 1(1):1-10. http://www.scientificoajournals.org/pdf/johd .007.pdf 
5. Perschbacher S. Interpretation of panoramic radiographs. Australian Dental Journal. 2012; 57(1 Suppl): 40-5. https://www.ncbi.nlm.nih.gov/pubmed/2 2376096

6. Venkatraman S, Gowda JS, Kamarthi N. Unusual ghost image in a panoramic radiograph. Dentomaxillofac Radiol. 2011; 40(6): 397-9. https://www.ncbi.nlm.nih.gov/pmc/articles/ PMC3520343/

7. Lakshman AR, Kannepady SH, Kalkur C. Mental foramen mimicking as periapical pathology - A case report. Journal of Health Sciences. 2014; 4(2):126-9. https://www.jhsci.ba/ojs/index.php/jhsci/arti cle/view/149/146

8. Avsever H, Gunduz K, Ozgedik S, Ozturk HP, Ozarslanturk S, Orhan K. Case report multiple accessory mental foramen: a rare anatomical finding. Dentistry Adv Res. 2017; 2(4): 1-4. https://www.gavinpublishers.com/admin/ass ets/articles_pdf/1510458678article_pdf1162 742222.pdf

9. Ramugade MM, Sonkurla SP, Naik RA. Comprehensive management of misdiagnosed periapical pathology mimicking the mental foramen using conebeam computed tomography as a diagnostic aid - a rare case report. Acta Scientific Dental Science. 2017; 1(1): 57-62. https://actascientific.com/ASDS/ASDS-010010.php

10. More CB, Das S, Gupta S, Patel P, Saha N. Stafne's bone cavity: a diagnostic challenge. J Clin Diagn Res. 2015; 9(11): ZD16-9. https://www.ncbi.nlm.nih.gov/pmc/articles/ PMC4668534/

11. Cartes G, Garay I, Deana NF, Navarro P, Alves N. Mandibular canal course and the position of the mental foramen by panoramic $\mathrm{X}$-ray in chilean individuals. Biomed Res Int. 2018; 2018: 1-10. https://www.ncbi.nlm.nih.gov/pubmed/2 $\underline{9984228}$

12. Ok E, Gungor E, Colak M, Altunsoy M, Nur BG, Aglarci OS. Evaluation of the relationship between the maxillary posterior teeth and the sinus floor using cone-beam computed tomography. Surg Radiol Anat. 2014; $\quad 36(9)$ : $\quad$ 907-14. https://www.ncbi.nlm.nih.gov/pubmed/2487 $\underline{4032}$

13. Imada TSN, Silva LMP, Fernandes R, Centurion BS, Oliveira-Santos C, Honório HM, Fischer IR, Rubira-Bullen. Accessory mental foramina: prevalence, position, and diameter assessed by cone-beam computed tomography and digital panoramic radiographs. Clin Oral Implants Res. 2014; 25(2): 94-9.

https://www.ncbi.nlm.nih.gov/pubmed/2 3167944

14. Konsil Kedokteran Indonesia. Standar kompetensi dokter gigi indonesia. Jakarta. Konsil kedokteran Indonesia; 2015. p.13.

15. İlgüy D, İlgüy M, Dölekoğlu ZS, Ersan N, Fişekçioğlu E. Evaluation of radiological anatomy knowledge among dental students. Yeditepe Dental J. 2017; 31-6.

https://www.journalagent.com/yeditepe/ pdfs/YDJ 13 3 3 3 31 36.pdf

16. Maeda N, Hosoki H, Yoshida M, Suito H, Honda E. Dental students' levels of understanding normal panoramic anatomy. J Dent Sci. 2018; 13(4): 374-7. https://www.ncbi.nlm.nih.gov/pmc/articl es/PMC6388826/

17. Iannuci JM, Howerton LJ. Dental radiography principles and technique. $5^{\text {th }}$ ed. Missouri: Elsevier; 2016.p.246-9; 315-30.

18. Karjodkar FR. Textbook of dental and maxillofacial radiology. $2^{\text {nd }}$ ed. Jaypee brothers medical publishers; 2009. p. 248-54.

19. Maeda N, Hosoki H, Yoshida M, Suito H, Honda E. Dental students' levels of understanding normal panoramic anatomy. J Dent Sci. 2018; 13(4): 374-7. https://www.ncbi.nlm.nih.gov/pmc/articl es/PMC6388826/ 